Jacob S. Matubis, MD ${ }^{1,2}$

Karen June P. Dumlao, MD²

Ryner Jose C. Carrillo, MD, MSc ${ }^{1,2}$

'Department of Anatomy

College of Medicine

University of the Philippines Manila

${ }^{2}$ Department of Otorhinolaryngology

Philippine General Hospital

University of the Philippines Manila
Correspondence: Dr. Jacob S. Matubis

Department of Otorhinolaryngology

Ward 10, Philippine General Hospital

University of the Philippines Manila

Taft Avenue, Ermita, Manila 1000

Philippines

Phone: (632) 5264360

E-mail: jacobmatubis@yahoo.com

Reprints will not be available from the author.

The authors declared that this represents original material that is not being considered for publication or has not been published or accepted for publication elsewhere, in full or in part, in print or electronic media; that the manuscript has been read and approved by all the authors, that the requirements for authorship have been met by each author, and that each author believes that the manuscript represents honest work.

Disclosures: The authors signed disclosures that there are no financial or other (including personal) relationships, intellectual passion, political or religious beliefs, and institutional affiliations that might lead to a conflict of interest.

Presented at the Descriptive Research Contest (1st place) Philippine Society of Otolaryngology-Head and Neck Surgery, GlaxoSmithKline (GSK) Bldg., Chino Roces Ave., Makati City, Philippines, October 11, 2010.

\section{The Recurrent Laryngeal Nerve in Relation to the Inferior Thyroid Artery in Adult Filipino Cadavers}

\begin{abstract}
Objective: To describe the anatomic relationship of the recurrent laryngeal nerve and the inferior thyroid artery in adult cadavers in the Philippines and to compare the proportions of these anatomic relationships with those reported in the foreign literature.
\end{abstract}

\section{Methods:}

Design: Descriptive, cross-sectional

Setting: University of the Philippines College of Medicine Anatomy Laboratory

Subjects: Fifty-four (54) preserved cadavers (108 sides) dissected within a period from June 2008 to Aug 2010. The anatomy and position of both the right and the left recurrent laryngeal nerves (RLN) and inferior thyroid arteries (ITA) were noted. The RLN was further classified into two variations: non-branching or branching prior to insertion at the cricothyroid joint under the inferior constrictor muscle. The ITA was also classified into non-branching and branching. The results were compared to two foreign studies using a Z-test for two proportions.

Results: Fifty four (54) cadavers (108 sides) were dissected. Among the cadavers, both the recurrent laryngeal nerves and inferior thyroid arteries had a maximum of two branches although both the RLNs and ITAs for both the right and left sides were mostly non-branching. The right side of one cadaver was noted to have both a branching RLN and a branching ITA. There were no non-recurrent laryngeal nerves seen among the 54 cadavers.

For both left and right sides, the RLN was mostly dorsal to the ITA. Branching RLNs was mostly dorsal to a non-branching ITAs. Most of the non-branching RLNs were dorsal to the ITAs. Nonbranching RLNs were usually dorsal to the ITA.

The local patterns of the course of the RLN in relation to the ITA approximates those of Chinese where there is predominance of the RLN dorsal to the ITA but differs from those of Brazilians where the RLN is usually between ITA branches.

Conclusion: There are multiple anatomical variations regarding the relationship of the RLN and the ITA. The anatomic variation among Asians may be different from Brazilians. The surgeon's knowledge of the possible various configurations of the RLN and ITA should be able to help in identification and preservation of the RLN and prevention of complications in thyroid surgery.

Keywords: recurrent laryngeal nerve, inferior thyroid artery, thyroid surgery, Filipino cadavers, anatomical variations

Philipp J Otolaryngol Head Neck Surg 2011; 26 (2): 13-17

(C) Philippine Society of Otolaryngology - Head and Neck Surgery, Inc 


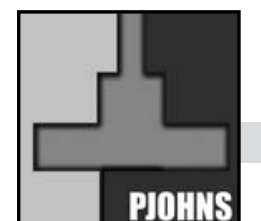

ORIGINAL ARTICLES

Philippine Journal Of Otolaryngology-Head And Neck Surgery

Vol. 26 No. 2 July - DeCEMBER 2011

A surgeon's knowledge of surgical anatomy and its variations is essential to prevent complications in any thyroid surgery. Modern technology has tried to minimize these problems but many patients still suffer recurrent laryngeal nerve complications which may include dysphonia, aspiration and even difficulty in breathing. A study of 624 thyroidectomy patients with 1076 nerves at risk by Steurer et al. showed $2.4 \%$ had temporary RLN palsy and $0.3 \%$ had permanent RLN paralysis. ${ }^{1}$

There are several surgical landmarks used to locate the recurrent laryngeal nerve such as the RLN triangle described by Lore et al. which is bounded by the trachea / esophagus, the carotid artery / internal jugular vein and the inferior thyroid pole. ${ }^{2} \mathrm{~A}$ study by Uen et al. found the RLN to be within $3 \mathrm{~mm}$ of Berry's ligament with no nerve penetrating the ligament. ${ }^{3}$ The inferior cornu of the thyroid cartilage is also a landmark which indicates the point of entry of the nerve into the larynx. ${ }^{4}$ Identification of Zuckerkandl's tubercle is also important because it shows relations with the branches of the inferior thyroid artery and recurrent laryngeal nerve., ${ }^{5,6}$

A number of studies have established the relationship of the recurrent laryngeal nerve and the inferior thyroid artery. However, we do not know of any local study regarding the topic. This study aims to describe the anatomic relationship of the recurrent laryngeal nerve and the inferior thyroid artery in cadavers in the Philippines and to compare the proportions of these anatomic relationships with those reported in the foreign literature.

\section{METHODS}

Fifty-four preserved cadavers (108 sides) in the University of the Philippines College of Medicine Anatomy Laboratory were dissected from the period of June 2008 to August 2010. Two anatomists

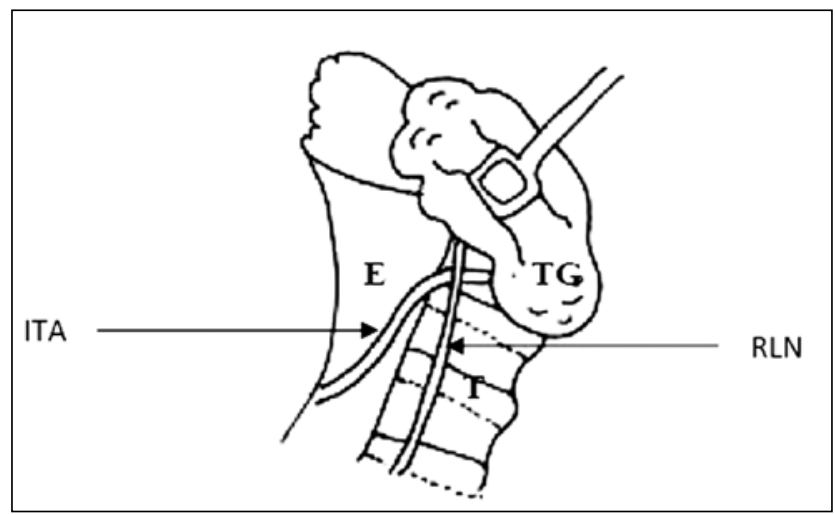

Figure 1. RLN ventral to ITA

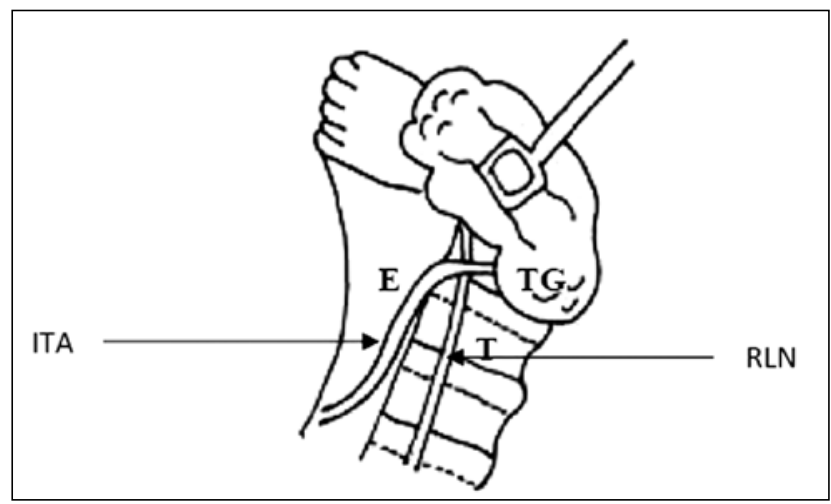

Figure 2. RLN dorsal to ITA.

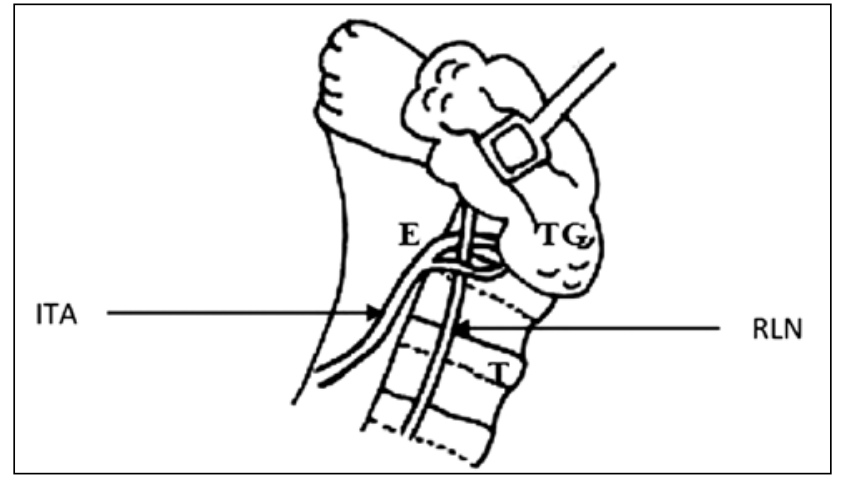

Figure 3. RLN between branches of ITA

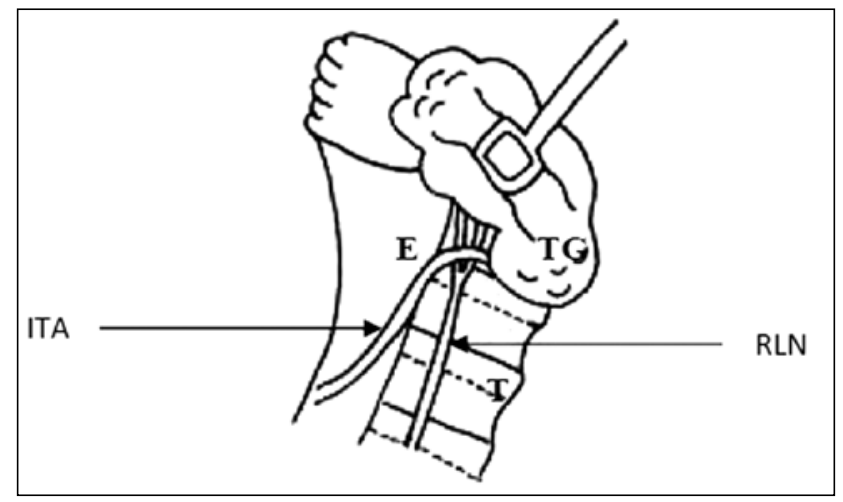

Figure 4. Branching RLN dorsal to ITA 
Table 1. Proportion of branching of recurrent laryngeal nerve and inferior thyroid artery.

\begin{tabular}{|c|c|c|c|c|c|c|}
\hline & \multicolumn{3}{|c|}{ Right side } & \multicolumn{3}{|c|}{ Left side } \\
\hline & $\begin{array}{c}\text { Non- } \\
\text { branching } \\
N(\%)\end{array}$ & $\begin{array}{c}\text { Branching } \\
\text { in } 2 \\
N(\%)\end{array}$ & $\begin{array}{l}\text { Total } \\
\mathrm{N}(\%)\end{array}$ & $\begin{array}{c}\text { Non- } \\
\text { branching } \\
N(\%)\end{array}$ & $\begin{array}{c}\text { Branching } \\
\text { in } 2 \\
N(\%)\end{array}$ & $\begin{array}{l}\text { Total } \\
\mathrm{N}(\%)\end{array}$ \\
\hline $\begin{array}{c}\text { Recurrent } \\
\text { Laryngeal } \\
\text { Nerve }\end{array}$ & $45(83)$ & $9(17)$ & $54(100)$ & 47 (87) & $7(13)$ & $54(100)$ \\
\hline $\begin{array}{l}\text { Inferior } \\
\text { Thyroid } \\
\text { Artery }\end{array}$ & $29(54)$ & $25(46)$ & $54(100)$ & $31(57)$ & $23(43)$ & $54(100)$ \\
\hline
\end{tabular}

RLN - Recurrent Laryngeal Nerve ; ITA - Inferior thyroid artery; N - Number of subjects

Table 2. Course of the Recurrent Laryngeal Nerve in relation to the Inferior thyroid artery:

\begin{tabular}{c|c|c|} 
Pattern & $\begin{array}{c}\text { Right } \\
\mathbf{N}(\%)\end{array}$ & $\begin{array}{c}\text { Left } \\
\mathbf{N}(\%)\end{array}$ \\
\hline RLN ventral to the ITA & $20(37.0)$ & $12(22.2)$ \\
\hline RLN dorsal to ITA & $\mathbf{2 5 ( 4 6 . 3 )}$ & $\mathbf{3 9}(\mathbf{7 2 . 2})$ \\
\hline RLN between branches of ITA & $9(16.7)$ & $3(5.6)$ \\
\hline TOTAL & $54(100)$ & $54(100)$
\end{tabular}

RLN - Recurrent Laryngeal Nerve ; ITA - Inferior thyroid artery; N - Number of subjects

Table 3. Relationship of branching RLN and non- branching ITA

\begin{tabular}{c|c|c|}
\multirow{2}{*}{ Pattern } & \multicolumn{2}{|c}{ Non-branching ITA } \\
\cline { 2 - 3 } & $\begin{array}{c}\text { Right } \\
\mathbf{N}(\%)\end{array}$ & $\begin{array}{c}\text { Left } \\
\mathbf{N}(\%)\end{array}$ \\
\hline Branching RLN ventral to the ITA & $1(1.9)$ & $2(3.7)$ \\
\hline Branching RLN dorsal to ITA & $5(9.3)$ & $2(3.7)$ \\
\hline $\begin{array}{c}\text { Branching RLN between } \\
\text { branches of ITA }\end{array}$ & $0(0)$ & $0(0)$ \\
\hline Non branching RLN & $48(88.8)$ & $50(92.6)$ \\
\hline TOTAL & $54(100)$ & $54(100)$ \\
\hline
\end{tabular}

RLN - Recurrent Laryngeal Nerve ; ITA - Inferior thyroid artery; N - Number of subjects

Table 4. Relationship of non-branching RLN and non-branching ITA

\begin{tabular}{c|c|c|}
\multirow{2}{*}{ Pattern } & \multicolumn{2}{|c|}{ Non-branching ITA } \\
\cline { 2 - 3 } & $\begin{array}{c}\text { Right } \\
\mathbf{N}(\%)\end{array}$ & $\begin{array}{c}\text { Left } \\
\mathbf{N}(\%)\end{array}$ \\
\hline $\begin{array}{c}\text { Non branching RLN ventral } \\
\text { to the ITA }\end{array}$ & $9(16.7)$ & $3(5.6)$ \\
\hline Non branching RLN dorsal to ITA & $11(20.4)$ & $21(38.9)$ \\
\hline $\begin{array}{c}\text { Non branching RLN between } \\
\text { branches of ITA }\end{array}$ & $1(1.9)$ & $0(0)$ \\
\hline Branching RLN & $33(61.1)$ & $30(55.6)$ \\
\hline TOTAL & $54(100)$ & $54(100)$ \\
\hline
\end{tabular}

RLN - Recurrent Laryngeal Nerve ; ITA - Inferior thyroid artery; N - Number of subjects performed the dissection. Medical histories and causes of death were unknown to the investigators. The anatomy and relationship of both the right and the left recurrent laryngeal nerves (RLN) and inferior thyroid arteries (ITA) were noted.

The RLN was classified into two variations: non-branching or branching prior to insertion at the cricothyroid joint under the inferior constrictor muscle. The ITA was also classified into non-branching and branching. The anatomical relationship of the RLN and ITA were classified into three types: the RLN was ventral to the ITA (Figure 1), RLN dorsal to the ITA (Figure 2) or RLN between branches of the ITA (Figure 3).

The results obtained were compared to the studies by Campos et al. of Brazil ${ }^{7}$ and Uen et al. of China ${ }^{3}$ using the Z Test for Two Proportions with the confidence level set at $95 \%$ and level of significance at $<0.05$.

\section{RESULTS}

Among the 54 cadavers, both the recurrent laryngeal nerves and inferior thyroid arteries had a maximum of two branches although both the RLNs and ITAs for both the right and left sides were mostly non-branching. The right side of one cadaver was noted to have both a branching RLN and a branching ITA. Table 1 shows the proportion of branching laryngeal nerves and inferior thyroid arteries. There were no non-recurrent laryngeal nerves seen among the 54 cadavers.

Table 2 shows the course of the RLN in relation to the ITA. For both left and right sides, the RLN was mostly dorsal to the ITA.

Table 3 shows the relationship of the branching RLNs and nonbranching ITAs. A branching RLN was mostly dorsal to a non-branching ITA. (Figure 4)

Table 4 shows the relationship of non-branching RLNs and nonbranching ITAs. Most of the non-branching RLN were dorsal to the non branching ITA. (Figure 2)

Table 5 shows the relationship of non-branching RLNs and a branching ITA. Most of the non-branching RLNs were dorsal to the branching ITA. It is important to note that in $10.19 \%$ the RLN coursed between the branches of the ITA.

Tables 6 and 7 compare the results of the present study with those of Uen and Campos. Campos et al. ${ }^{7}$ dissected 76 cadavers and yielded results shown in Table 6. All p values from the $Z$ test for two proportions were more than the level of significance of 0.05 .

Uen et al. ${ }^{3}$ dissected 60 cadavers with results shown in Table 7. The $p$ values of the RLN between branches of the ITA on the right and RLN dorsal to ITA on the left were below the level of significance of 0.05 . The rest of the $p$ values were more than the level of significance of 0.05 . 
Table 5. Relationship of non-branching RLN and a branching ITA

\begin{tabular}{c|c|c|}
\multirow{2}{*}{ Pattern } & \multicolumn{2}{|c}{ Branching ITA } \\
\cline { 2 - 3 } & $\begin{array}{c}\text { Right } \\
\mathbf{N}(\%)\end{array}$ & $\begin{array}{c}\text { Left } \\
\mathbf{N}(\%)\end{array}$ \\
\hline $\begin{array}{c}\text { Non branching RLN ventral to } \\
\text { the ITA }\end{array}$ & $8(14.8)$ & $4(7.4)$ \\
\hline $\begin{array}{c}\text { Non branching RLN dorsal to ITA } \\
\begin{array}{c}\text { Non branching RLN between } \\
\text { branches of ITA }\end{array}\end{array}$ & $6(11.1)$ & $13(24.1)$ \\
\hline Branching RLN & $8(14.8)$ & $3(5.6)$ \\
\hline TOTAL & $32(59.3)$ & $20(37.0)$ \\
\hline
\end{tabular}

RLN - Recurrent Laryngeal Nerve; ITA - Inferior thyroid artery; N - Number of subjects

Table 6. Comparison of proportions of the values from this study compared to the studies of Campos et al. ${ }^{7}$

\begin{tabular}{|c|c|c|c|c|}
\hline & Pattern & $\begin{array}{l}\text { Present } \\
\text { Study } \\
N=54\end{array}$ & $\begin{array}{c}\text { Campos }^{7} \\
\mathrm{~N}=76\end{array}$ & P Value \\
\hline \multirow{3}{*}{ 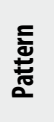 } & RLN ventral to the ITA & $37.0 \%$ & $38.0 \%$ & 0.1 \\
\hline & RLN dorsal to ITA & $46.3 \%$ & $11.3 \%$ & 4.3 \\
\hline & RLN between branches of ITA & $16.7 \%$ & $49.3 \%$ & 3.6 \\
\hline \multirow{3}{*}{ 壳 } & RLN ventral to the ITA & $22.2 \%$ & $18.1 \%$ & 0.3 \\
\hline & RLN dorsal to ITA & $72.2 \%$ & $37.1 \%$ & 3.8 \\
\hline & RLN between branches of ITA & $5.6 \%$ & $44.5 \%$ & 4.6 \\
\hline
\end{tabular}

*Level of Significance $\mathrm{P}<0.05$

RLN - Recurrent Laryngeal Nerve ; ITA - Inferior thyroid artery; $\mathrm{N}$ - Number of subjects

Table 7. Comparison of proportions of the values from this study compared to the studies of Uen et al. $^{5}$

\begin{tabular}{|c|c|c|c|c|}
\hline & & $\begin{array}{c}\text { Present } \\
\text { Study } \\
\mathrm{N}=54\end{array}$ & $\begin{array}{c}\text { Uen }^{5} \\
N=60\end{array}$ & P Value \\
\hline \multirow{3}{*}{$\begin{array}{l}\text { 폴 } \\
\text { 壳 }\end{array}$} & RLN ventral to the ITA & $37.0 \%$ & $20 \%$ & 1.8 \\
\hline & RLN dorsal to ITA & $46.3 \%$ & $61.6 \%$ & 1.5 \\
\hline & RLN between branches of ITA & $16.7 \%$ & $18.4 \%$ & -0.1 \\
\hline \multirow{3}{*}{ 壳 } & RLN ventral to the ITA & $22.2 \%$ & $8.3 \%$ & 1.8 \\
\hline & RLN dorsal to ITA & $72.2 \%$ & $70 \%$ & 0.0 \\
\hline & RLN between branches of ITA & $5.6 \%$ & $21.7 \%$ & 2.2 \\
\hline
\end{tabular}

*Level of Significance $P<0.05$

RLN - Recurrent Laryngeal Nerve ; ITA - Inferior thyroid artery; N - Number of subjects

The local patterns of the course of the RLN in relation to the ITA approximated those of Chinese where there is a predominance of the RLN dorsal to the ITA, but differs from Brazilians where the RLN is usually between ITA branches.

\section{DISCUSSION}

In the present study, $14.8 \%$ of the RLNs on either side were noted to branch in two prior to insertion in the cricothyroid junction. This study also found that $44.4 \%$ of the ITA branched in two. (Table 1) This situation could be very difficult and crucial for the surgeon and this may have a higher likelihood of nerve injury if the surgeon is not aware of the branching variations of the ITA and the RLN.

In this study, the RLN was frequently found dorsal to the ITA whereas the study of Campos et al. ${ }^{7}$ found the RLN more frequently between branches of the ITA. This difference was true for both right and left sides, and was statistically significant. Uen et al. ${ }^{3}$ noted the RLN more frequently passed between the ITA branches on the left side, but not the right. Again, the difference in proportions between their findings and those of this study was statistically significant.

Recurrent laryngeal nerve injury is a very disturbing complication of any thyroid surgery. It has psychosocial and functional impact and greatly affects quality of life especially among those who are highly dependent on the use of voice. ${ }^{8}$ The incidence may vary among countries, surgeons and specific types of thyroid surgery done and the type of thyroid disease. ${ }^{5}$

A meta-analysis by Schulte et al. ${ }^{5}$ noted permanent recurrent laryngeal nerve palsy in 999 out of 28,957 post thyroid surgery patients (3.5\%). However, studies they reviewed from the year 1997 onwards showed a marked decrease in permanent recurrent laryngeal nerve palsy to 114 out of $14,687(0.7 \%)$. This may reflect improvement in the technique of recurrent laryngeal nerve preservation or better awareness of the variable anatomy.

Numerous techniques have been described for preservation of the recurrent laryngeal nerve during thyroid surgery. Nerve-monitoring techniques include the use of intramuscular electromyography (EMG) and palpation of the cricothyroid after stimulation of the nerve with a disposable stimulator. ${ }^{9}$

Dralle et al. ${ }^{10}$ compared the outcomes of intra-operative nerve monitoring (IONM) versus visual nerve identification and concluded that the difference was not statistically significant. They also compared the outcomes of intra-operative nerve monitoring on top of visual nerve identification versus visual nerve identification alone. Again, they concluded that IONM on top of visual nerve identification did not lower the incidence of recurrent laryngeal nerve palsy.

Thomusch et al. ${ }^{11}$ analysed the postoperative RLN palsy rate in thyroid surgeries using IONM versus visual identification of the RLN. 
ORIGINAL ARTICLES

The use of IONM significantly decreased the early RLN palsy rate (3.3\%) versus visual identification (4.9\%). However, IONM showed only a slight advantage over visual identification on the permanent RLN palsy rate $(0.7 \%$ versus $0.9 \%)$ which was not statistically significant.

The gold standard for preservation of the recurrent laryngeal nerve during thyroid surgery is still visual anatomical identification. Proper dissection and anatomical identification of the RLN and all its branches is very important prior to the clamping of the ITA and all its branches. Other techniques which aim to preserve the RLN may be used only as an adjunct to the gold standard. In a setting where advances in technology are not readily available, the surgeon must be knowledgeable about the variations in the neurovascular anatomy of the thyroid gland to prevent complications of surgery.

\section{REFERENCES}

1. Steurer M, Passler C, Denk DM, Schneider B, Mancusi G, Schickinger B et al. Functional laryngeal results after thyroidectomy and extensive recurrent laryngeal nerve dissection without neuromonitoring - An analysis of more than 1000 nerves at risk. Eur Surg. 2003 Oct; 35(5): 262267.

2. Lore JM, Medina JE. An Atlas of Head and Neck Surgery. Fourth Edition. Pennsylvania: Elsevier; 2005.

3. Uen YH, Chen TH, Shyu JF, Shyr TM, Su CH, Chen JY, et al. Surgical anatomy of the recurrent laryngeal nerves and its clinical applications in chinese adults. Surgery Today. 2006; 36(4):312-315.

4. Wang $C$. The use of the inferior cornu of the thyroid cartilage in identifying the recurrent laryngeal nerve. Surg Gynecol Obstet. 1975 Jan;140(1):91-4.

5. Schulte KM, Roher HD. Complications in the surgery of benign thyroid. Acta Chir, Austriaca 2001; 33(4):164-172.

6. Yalçin B, Poyrazoĝlu Y, Ozan H. Relationship between Zuckerkandl's tubercle and the inferior laryngeal nerve including the laryngeal branches. Surgery Today. 2007 Jan;37(2)109-113.

7. Campos BA, Henriques PRF. Relationship between the recurrent laryngeal nerve and the inferior thyroid artery: a study in corpses. Rev. Hosp. Clín. Fac. Med. S. Paulo 2000 Nov; 55(6):195-200.

8. Sturniolo G, D'Alia C, Tonante A, Gagliano E, Taranto F, Lo Schiavo MG. The recurrent laryngeal nerve related to thyroid surgery. Am J Surg. 1999 June;177(6):485-8.

9. Shindo M, Chheda NN. Incidence of vocal cord paralysis with and without recurrent laryngeal nerve monitoring during thyroidectomy. Arch Otolaryngol Head Neck Surg. 2007 May;133(5):481-485.

10. Dralle H, Sekulla C, Lorenz K, Brauckhoff M, Machens A. Intraoperative monitoring of the recurrent laryngeal nerve in thyroid surgery. World J Surg $2008 \mathrm{Jul}$; 32(7):1358-1366.

11. Thomusch O, Sekulla C, Timmermann W, Neumann HJ, Kruse E, Muhlig HP, et al. Intraoperative neuromonitoring in thyroid surgery - Results of the German prospective multicentre study. Eur. Surg. 2003; 35(5):240-245. 